\title{
RNase-assisted RNA chromatography
}

\section{GRACJAN MICHLEWSKI and JAVIER F. CÁCERES}

Medical Research Council Human Genetics Unit, Institute of Genetics and Molecular Medicine, Western General Hospital, Edinburgh EH4 2XU, United Kingdom

\begin{abstract}
RNA chromatography combined with mass spectrometry represents a widely used experimental approach to identify RNA-binding proteins that recognize specific RNA targets. An important drawback of most of these protocols is the high background due to direct or indirect nonspecific binding of cellular proteins to the beads. In many cases this can hamper the detection of individual proteins due to their low levels and/or comigration with contaminating proteins. Increasing the salt concentration during washing steps can reduce background, but at the cost of using less physiological salt concentrations and the likely loss of important RNA-binding proteins that are less stringently bound to a given RNA, as well as the disassembly of protein or ribonucleoprotein complexes. Here, we describe an improved RNA chromatography method that relies on the use of a cocktail of RNases in the elution step. This results in the release of proteins specifically associated with the RNA ligand and almost complete elimination of background noise, allowing a more sensitive and thorough detection of RNA-binding proteins recognizing a specific RNA transcript.
\end{abstract}

Keywords: RNA-binding proteins; RNA chromatography; RNases; microRNA processing; alternative splicing

\section{INTRODUCTION}

Newly transcribed messenger RNAs associate with a large variety of RNA-binding proteins (RBPs) to form messenger ribonucleoprotein complexes (mRNPs), which influence the life cycle of these RNAs both in the nucleus and in the cytoplasm (for reviews, see Dreyfuss et al. 2002; Glisovic et al. 2008). Thus, mRNPs are the main substrates of all RNA processing events in the cell, including constitutive and alternative pre-mRNA splicing (Singh and Valcarcel 2005; Wahl et al. 2009) and polyadenylation in the nucleus, but also mRNA export and cytoplasmic events including mRNA localization (Kelly and Corbett 2009; Martin and Ephrussi 2009), translational regulation (Sonenberg and Hinnebusch 2009), and mRNA turnover (Houseley and Tollervey 2009). All of these cellular processes, which are central to gene expression, rely on well-defined RNP complexes, which are highly dynamic and tightly regulated. Ribonucleoprotein (RNP) complexes are not exclusive to messenger RNAs, but indeed every cellular RNA, including long noncoding RNAs

Reprint requests to: Gracjan Michlewski, Medical Research Council Human Genetics Unit, Western General Hospital, Edinburgh EH4 2XU, United Kingdom; e-mail: Gracjan.Michewski@hgu.mrc.ac.uk; fax: 44-131-467-8456; or Javier F. Cáceres, Medical Research Council Human Genetics Unit, Western General Hospital, Edinburgh EH4 2XU, United Kingdom; e-mail: Javier.Caceres@hgu.mrc.ac.uk; fax: 44-131-467-8456. Article published online ahead of print. Article and publication date are at http://www.rnajournal.org/cgi/doi/10.1261/rna.2136010. and microRNAs (miRNAs), are also complexed with proteins, forming different types of RNP complexes (Kim et al. 2009). This ever-growing world of RNA continuously supplies new cellular mechanisms and RNPs that need to be characterized.

Many different experimental approaches have been developed to study the composition of RNP complexes. Selected evolution of ligands through exponential enrichment (SELEX) is a technique widely used to identify cellular RNA targets for an individual RNA-binding protein), and it relies on the selection of high-affinity binding sites from randomized pools of RNA sequences (Ellington and Szostak 1990; Tuerk and Gold 1990). A modification of the SELEX protocol, termed genomic SELEX, relies on the use of genomic sequences rather than random pools, resulting in the identification of authentic protein-binding RNA sequences (Singer et al. 1997; Lorenz et al. 2006). An alternative approach is the use of a variation of the widely used chromatin immunoprecipitation (ChIP), termed ribonucleoprotein immunoprecipitation (RIP), to study nascent RNA-protein interactions in vivo (Niranjanakumari et al. 2002). RIP has also been combined with microarrays for the isolation of endogenous mRNP complexes and identification of the associated mRNAs on a genome scale - a method known as RIP-Chip (for review, see Baroni et al. 2008). A recently developed protocol, cross-linking and immunoprecipitation (CLIP) (Ule et al. 2003, 2005), and its high-throughput sequencing derivatives (HITS-CLIP or CLIP-Seq) (Licatalosi et al. 2008; 
Chi et al. 2009; Sanford et al. 2009; Yeo et al. 2009; Zisoulis et al. 2010) are being used for the identification of cellular RNA targets for many different RBPs. The different CLIP protocols use an in vivo photo-cross-linking step that is followed by highly stringent immunoprecipitation conditions, so that only endogenous RNA targets directly bound to the protein of interest are selected.

In contrast, when the main goal is the identification of proteins that are bound to specific RNA transcripts, RNA chromatography combined with mass spectrometry has been the method of choice (Matunis et al. 1994) (for review, see Hegarat et al. 2008). Several methods have been developed to attach RNAs to a solid support and for the elution of RNAbinding proteins. For instance, an affinity resin consisting of periodate-oxidized double-stranded RNA covalently attached to agarose-adipic acid hydrazide was shown to have increased specificity for known double-stranded RNA-binding proteins (Langland et al. 1995). Small, reversibly biotinylated RNAs can be attached to a solid support by binding to avidin and used as ligands or alternatively, they can be hybridized to another RNA, which then acts as the ligand. To facilitate elution of bound proteins, incorporation of a disulfide bond in the linker arm connecting biotin to the RNA allows dissociation of the RNA from avidin under mild conditions (Ruby et al. 1990).

One of the major limitations of the different RNA chromatography methods is the presence of a high background, which hampers detection of potentially important proteins, either due to their low expression levels or their comigration with contaminating proteins. It is possible to select for more stringent binding by increasing the salt concentration in various steps of the RNA chromatography procedure. This in turn reduces the background noise, but at the same time can also result in less physiological salt concentrations and may cause the loss of important RBPs that are less stringently bound to a given RNA. Here, we describe an improved RNA chromatography method, which relies on an RNase-mediated elution step that almost completely eliminates background noise, allowing more sensitive and thorough detection of RBPs binding to specific RNA transcripts.

\section{RESULTS AND DISCUSSION}

\section{$A$ rationale for the need of RNase-assisted RNA chromatography}

Various RNA chromatography methods (here collectively called standard chromatography) have common steps, which include: (1) coupling the RNA transcript of interest to beads; (2) incubating beadcoupled RNAs in cell extracts, followed by stringent washes; (3) denaturing the bead-coupled RNP complex, followed by SDS electrophoresis; and (4) mass spectrometry of specific protein bands (Fig. 1). RNA could be immobilized on the beads by different methods, such as covalent binding (Buratti et al. 2001), biotin-streptavidin affinity (Grabowski and Sharp 1986), or by sequence complementary to DNA or RNA prebound to the beads (Heo et al. 2009).

Regardless of the method used, the presence of beads during RNA affinity chromatography poses a technical challenge as they often bind proteins nonspecifically, resulting in substantial background noise. In order to eliminate this problem, without a need to increase the buffer stringency, we modified the existing RNA chromatography by treating the bead-coupled RNP complexes with a high concentration of ribonucleases prior to SDS electrophoresis (Fig. 1). This step enables the release of only those proteins that are directly or indirectly bound to the RNA, and at the same time discards all of the contaminating proteins resulting from nonspecific binding to the beads.

\section{Identification of proteins bound to pri-microRNA terminal loops}

Using standard RNA chromatography, we have previously shown that the terminal loops (TLs) of two microRNAs (miRNAs) — pri-let-7a-1 and pri-miR-101-1_are bound by common, but also unique, proteins (Michlewski et al. 2008). Both terminal loops were bound by hnRNP A1, whereas let7a-1 and miR-101-1 terminal loops were specifically bound by hnRNP L and PTB, respectively (Fig. 2A). Here, we replicated those experiments using both standard (Figs. 2B, 3A) and RNase-assisted RNA chromatography with RNase A/T1 (Figs. 2C,D, 3B). Notably, while using the same buffer conditions and number of washes, contamination coming from nonspecific proteins binding to the beads was substantial in

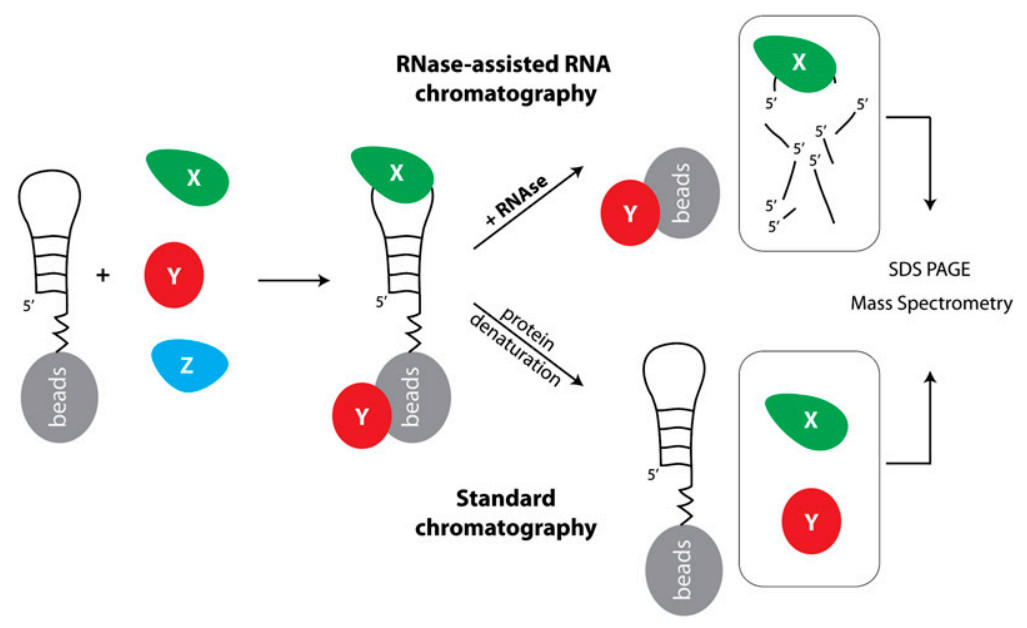

FIGURE 1. Schematic outline of the RNase-assisted RNA chromatography method. An RNA molecule is covalently attached to the agarose beads and then incubated with protein extracts (X, Y, and Z denote different cellular proteins). Next, the RNA-protein complexes are released from the beads by RNase treatment, followed by SDS electrophoresis and mass spectrometry. 
A

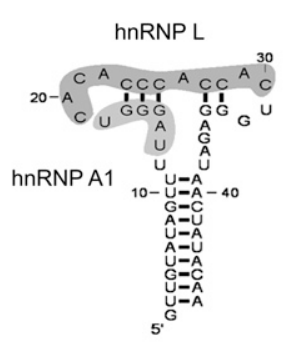

let-7a-1 TL

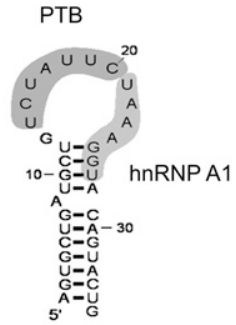

miR-101-1 TL
B

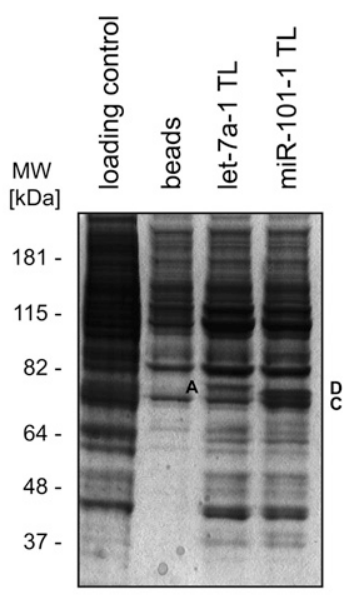

D

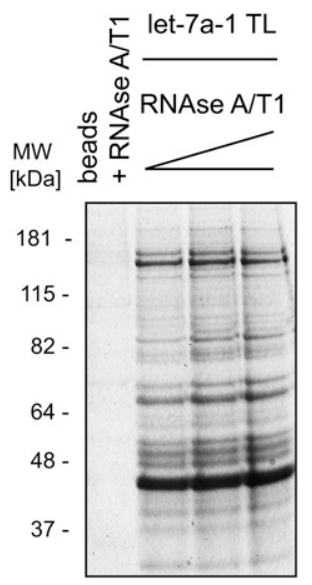

FIGURE 2. Isolation of proteins binding to precursor miRNA terminal loops. ( $A$ ) Predicted structures of apical regions with highlighted putative protein-binding sites for let-7a-1 and miR-101-1. (B) Standard and (C) RNase-assisted RNA chromatography of let-7a-1 and miR101-1 terminal loops in HeLa nuclear extracts. Bands denoted A and B correspond to selected proteins highly enriched in the let-7a-1 chromatograms, hnRNP L, and nucleolin, respectively. Bands C and D correspond to PTB protein, which is highly enriched in the miR-101-1 chromatograms. RNase-assisted RNA chromatography was performed using RNase A/T1 or RNase I, as indicated. (D) RNase-assisted RNA chromatography with let-7a-1 TL and increasing concentration of RNase A/T1 $(1,2.5$, and $5 \mu \mathrm{L}$ per reaction).

standard chromatography but was drastically reduced to almost undetectable levels when using RNase in the elution step (Fig. 2B-D). Consistently, Western blot analysis for hnRNP L and PTB displayed significant reduction in binding of those proteins to the beads, thus making the analysis far cleaner (Fig. 3). This was possible, as the beads with nonspecific bound proteins were separated by centrifugation from the degraded RNA and the now released RBPs. Importantly, such significant reduction of background noise revealed several additional proteins specifically binding to pri-miRNA terminal loops. Mass spectrometry analysis of a few selected bands confirmed previous results and provided evidence that the pri-let-7a-1 terminal loop is specifically binding nucleolin, a phosphoprotein involved in the synthesis and maturation of ribosomes (for review, see Ginisty et al. 1999). When using standard chromatography, this $110-\mathrm{kDa}$ protein comigrated with the contaminating proteins; thus, it was virtually undetectable (Fig. 2C, band B). Experiments are currently under way to elucidate the role of nucleolin in the processing of pri-let-7a-1. This result highlights the applicability of this novel method to the identification of RBPs, which remain undetectable when using traditional RNA chromatography procedures.

Next, we wanted to establish the optimal conditions for the use of RNases as an elution agent in RNA chromatography. To do so, we performed RNase-assisted RNA chromatography on the pri-let-7a-1 and pri-miR-101-1 terminal loops using several RNA cleaving reagents. We found that high concentrations of lead ions- $\mathrm{Pb}$ (II) or micrococcal nuclease (MNase) provided unsatisfactory results (data not shown). In contrast, RNA chromatography using either a mixture of ribonuclease $\mathrm{A}$ and $\mathrm{T} 1$ (RNase $\mathrm{A} / \mathrm{T} 1$ ) or ribonuclease I (RNase I) resulted in a very similar electrophoretic pattern of specific proteins binding to the corresponding pri-miRterminal loops (Fig. 2C). We found a better resolution of high molecular weight bands in the chromatograms resulting from RNase A/T1 cleavage; hence, we decided to use this RNA cleaving reagent in subsequent analysis. Next, we wanted to establish the optimal concentration of RNase A/T1 for elution of proteins binding to the pri-let-7a-1 terminal. We observed that the highest concentration of RNase A/T1 provided the best results, most likely due to complete degradation of the let-7a-1 terminal loop sequence bound to the beads, causing the release of all of the RNAbound proteins (Fig. 2D). The relative performance of all RNA cleaving reagents tested for RNase-assisted RNA chromatography is summarized in Table 1 . We speculate that the use of additional RNases, such as RNase V1, which recognizes double-stranded RNA, could be an alternative when dealing with highly stable RNA substrates.

\section{Identification of proteins binding to transcripts derived from fibronectin EDA splicing enhancer}

Next, we sought to test our improved chromatography method using a recognized example of an RNA sequence bound by a specific protein. Here, we took advantage of 


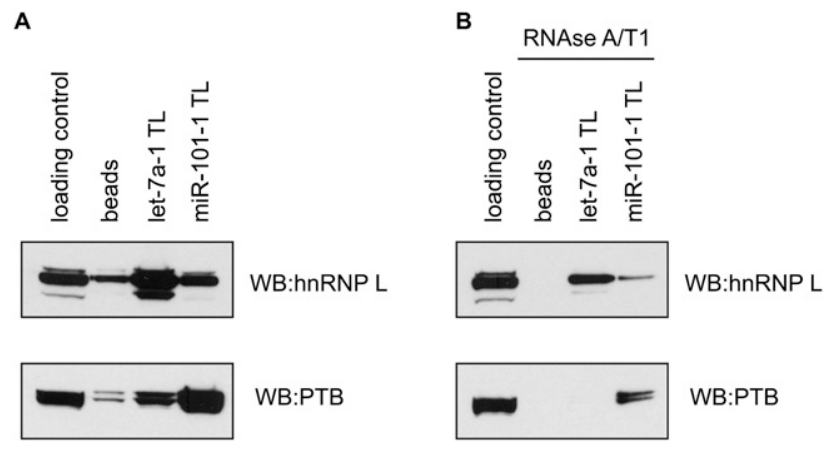

FIGURE 3. Western blot analysis of hnRNP L and PTB carried out on the let-7a-1 TL and miR-101-1 TL transcripts-derived from standard $(A)$ or RNase-assisted RNA chromatograms $(B)$.

a very thoroughly characterized exonic-splicing enhancer (ESE), derived from the EDA alternative exon of the fibronectin gene, which is known to recruit the SR protein SF2/ASF (Lavigueur et al. 1993; Cramer et al. 1999; Buratti et al. 2004). Standard chromatography, with wild-type (Fig. 4A, EDA) and mutated EDA transcripts (Fig. 4A, EDAmt), provided marginal discrimination between the control, EDA, and EDAmt lanes (Fig. 4B, top, left). Interestingly, Western blot analysis revealed that SF2/ASF displayed an expected enrichment in the wild-type EDA chromatograms (Fig. 4B, bottom). Importantly, in the same reaction and washing conditions, RNase-assisted RNA chromatography provided a background-free pattern of specific proteins binding to the EDA and EDAmt transcripts (Fig. 4C, top). The proteins specifically binding to the EDA RNA were identified as hnRNP A2/B1 and SF2/ASF. Additionally, two bands derived from EDAmt RNA chromatography using RNase A/T1 were identified as "far upstream element-binding protein 1" (FUBP1) and "far upstream element-binding protein 2" (FUBP2), also known as KSRP (Min et al. 1997). The specificity of protein binding to the EDA sequence and the absence of background noise were confirmed by Western blot against SF2/ASF (Fig. 4B,C, bottom).

\section{Identification of proteins binding to an exonic splicing silencer in exon 4 of the CD45 gene}

To assess the general applicability of this novel method we performed the analysis of an exonic splicing silencer (ESS1), derived from the variable exon 4 of the CD45 gene (Rothrock et al. 2005). This exonic silencer has been shown to mediate basal exon skipping in resting $\mathrm{T}$ cells through the binding of hnRNP L to a welldefined, CA-rich sequence within this element. Several other RNA-binding proteins, including PSF and a few members of the hnRNP family of proteins were shown to bind ESS1 and coregulate exon 4 repression in response to T-cell activation (Melton et al. 2007). Standard chromatography, performed with a transcript comprising the ESS1 element, which contains high-affinity binding sites for hnRNP $\mathrm{L}$ and its mutated counterpart transcript (ESS1mt) (Fig. 5A), resulted in an overall modest discrimination between the control, ESS1, and its mutant counterpart (ESS1mt) (Fig. 5B, top,), but led to a complete lack of discrimination in the high molecular weight ranges. In agreement with previous reports, hnRNP L was enriched in the ESS1 chromatography when assayed by Western blot analysis (Fig. 5B, bottom). Notably, our new method significantly improved detection of specific proteins binding to the ESS1 sequence, providing background-free patterns for both ESS1 and ESS1mt chromatography, apart from a visible 19$\mathrm{kDa}$ band corresponding to RNase A/T1 (Fig. 5C, top). Selected protein bands, which were specific for the ESS1 chromatogram, were subjected to mass spectrometry and resulted in the identification of hnRNP L and hnRNP K, as previously reported (Melton et al. 2007). Interestingly, the very low background resulting from this new protocol led to the identification of three RNA-binding proteins specifically binding to the ESS1 element, i.e., FUBP1, FUBP2, and FUBP3, which previously escaped detection by other standard chromatography methods. Finally, the specificity of protein binding to the ESS1 transcript and the absence of background noise were confirmed by Western blot against hnRNP L (Fig. 5B,C, bottom).

In summary, we have developed an improved RNA chromatography method, performed under similar experimental conditions to standard RNA chromatography, but with a novel elution step that provides more sensitive and complete detection of proteins binding to a specific transcript. We have demonstrated the usefulness of this method for the identification of proteins recognizing terminal loops of miRNAs, as well as of proteins binding to a specific exonic splicing enhancer or to an exonic splicing silencer, and influencing alternative splicing. In the future, this technique could be further developed to capture protein-binding partners of individual RNA motifs, embedded in full-length transcripts, by using sequence-specific cleaving reagents such as RNAzymes, DNAzymes, or oligonucleotides coupled with RNase H. Altogether, our results strongly suggest a competitive advantage for the use of RNase-assisted RNA chromatography to identify complex patterns of RBPs that recognize specific RNA transcripts.
TABLE 1. Relative performance of tested, RNA cleavage reagents used in RNase-assisted RNA chromatography

\begin{tabular}{lccccc}
\hline $\begin{array}{l}\text { RNA } \\
\text { cleaving reagent }\end{array}$ & $\mathrm{Pb}(\mathrm{II})$ & MNase & RNase I & $\begin{array}{c}\text { RNase A/T1 } \\
\text { (low } \\
\text { concentration) }\end{array}$ & $\begin{array}{c}\text { RNase A/T1 } \\
\text { (high } \\
\text { concentration) }\end{array}$ \\
\hline Relative performance & - & + & ++ & ++ & +++ \\
\hline Note: $(-)$ inefficient; $(+)$ less efficient; $(++)$ efficient; and (+++) most efficient. &
\end{tabular}


EDA - CCUGAUGGUGAAGAAGACAUGCA EDAmt - CCUGAUGGUGUUGUUGUCAUGCA
B

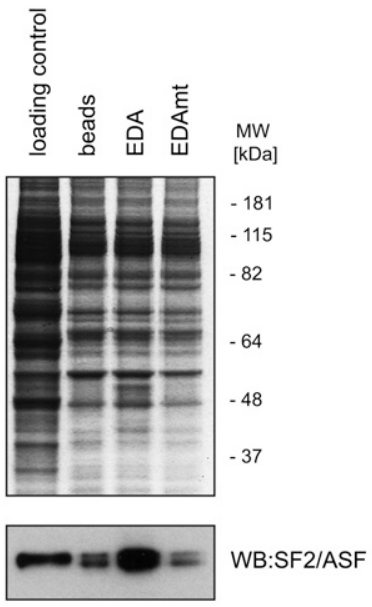

C

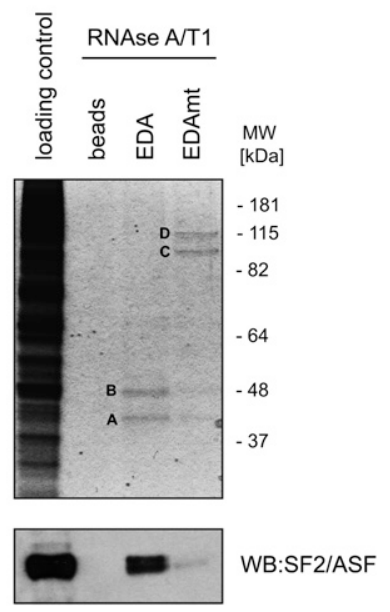

FIGURE 4. Isolation of proteins binding to a transcript containing the fibronectin EDA exonic splicing enhancer-EDA or a mutant version-EDAmt. (A) Sequences of EDA and EDAmt RNAs are shown. $(B)$ Standard and $(C)$ RNase-assisted RNA chromatography of EDA and EDAmt transcripts in HeLa nuclear extracts. Bands denoted A and $\mathrm{B}$ correspond to SF2/ASF and to hnRNP A2/B1, respectively, whereas bands $\mathrm{C}$ and $\mathrm{D}$ indicate FUBP1 and FUBP2, respectively. (Bottom) SF2/ASF Western blot analysis of the corresponding RNA chromatograms.

\section{MATERIALS AND METHODS}

\section{RNase-assisted RNA chromatography protocol}

This method is based on the affinity purification method, as described by the Baralle laboratory (Buratti et al. 2001).

1. Cold RNA ( $1 \mu \mathrm{mol})$ is incubated in a $200-\mu \mathrm{L}$ reaction containing $0.1 \mathrm{M} \mathrm{NaOAc}(\mathrm{pH}$ 5.0) and $5 \mathrm{mM}$ sodium m-periodate (Sigma) for $1 \mathrm{~h}$ in the dark at RT.

2. After ethanol precipitation, RNA is resuspended in $500 \mu \mathrm{L}$ of $0.1 \mathrm{M} \mathrm{NaOAc}$ (pH 5.0).

3. Adipic acid dehydrazide agarose bead $50 \%$ slurry $(250 \mathrm{uL})$ (Sigma) is washed four times in $10 \mathrm{~mL}$ of $0.1 \mathrm{M} \mathrm{NaOAc}$ ( $\mathrm{pH} 5.0$ ). After the final wash, the beads are resuspended in $200 \mu \mathrm{L}$ of 0.1 $\mathrm{M} \mathrm{NaOAc}$ ( $\mathrm{pH}$ 5.0) and added to the periodate-treated RNA.

4. RNA with the beads is incubated overnight at $4^{\circ} \mathrm{C}$. Then the bound RNAs are washed three times in $1 \mathrm{~mL}$ of $2 \mathrm{M} \mathrm{KCl}$ and three times in $1 \mathrm{~mL}$ of buffer $\mathrm{D}$ (20 mM Tris- $\mathrm{HCl}$ at $\mathrm{pH} 7.9,20 \%$ p/v glycerol, $0.1 \mathrm{M} \mathrm{KCl}, 0.2 \mathrm{mM}$ EDTA, $0.5 \mathrm{mM}$ dithiothreitol, $0.2 \mathrm{mM}$ PMSF).

5. The RNA coupled to beads is incubated with $40 \%$ v/v HeLa cell nuclear extract, $1.5 \mathrm{mM} \mathrm{MgCl}_{2}, 25 \mathrm{mM}$ creatine-phosphate, and $5 \mathrm{mM}$ ATP for $30 \mathrm{~min}$ at $37^{\circ} \mathrm{C}$, shaking at $400 \mathrm{rpm}$, in a $650 \mu \mathrm{L}$ final volume.

6. Next, reactions are washed four times with $1 \mathrm{~mL}$ of buffer $\mathrm{D}$ containing $1.5 \mathrm{mM} \mathrm{MgCl}$ and twice with Milli-Q water.

7. After the final centrifugation the RNA coupled to the beads is incubated in a $60 \mu \mathrm{L}$ reaction containing $10 \mathrm{mM}$ Tris- $\mathrm{HCl}(\mathrm{pH}$
7.2), $1 \mathrm{mM} \mathrm{MgCl} 2,40 \mathrm{mM} \mathrm{NaCl}$, and $5 \mu \mathrm{L}$ of $\mathrm{A} / \mathrm{T} 1$ ribonuclease mix (Ambion), or other RNA cleaving reagents, for $30 \mathrm{~min}$ at $37^{\circ} \mathrm{C}$, shaking at $1400 \mathrm{rpm}$ for $10 \mathrm{sec}$ every minute. Several time points, ranging from 5 to $60 \mathrm{~min}$ were tested, but $30 \mathrm{~min}$ was found to give an optimal pattern of released proteins. Furthermore, increasing the time points did not improve the final result. The aim of this step is to hydrolyze all RNA coupled to the beads, thus releasing only the proteins that are directly or indirectly bound to the RNA, but not to beads themselves. The concentration of RNases in the $\mathrm{A} / \mathrm{T} 1$ in the mix is $500 \mathrm{U} / \mathrm{mL}$ for RNase A and 20,000 U/mL for RNase T1, respectively.

8. The resulting reaction is then centrifuged for $1 \mathrm{~min}$ at $4^{\circ} \mathrm{C}$ and the supernatant is collected and analyzed by SDS/PAGE for proteins binding to cleaved RNA. This step separates the hydrolyzed RNA with its bound proteins from the bead-attached, contaminating proteins.

\section{RNA substrates}

The following substrate RNAs were used: let-7a-1 loop (5'-GUUG UAUAGUUUUAGGGUCACACCCACCACUGGGAGAUAACUA UACAAUC-3'); miR-101-1 loop (5'-AGUGCUGAUGCUGUCUA UUCUAAAGGUACAGUACUG-3'); EDA (5'-CCUGAUGGUGA AGAAGACAUGCA-3'); EDAmt (5'-CCUGAUGGUGUUGUUG UCAUGCA-3'); ESS1 (5' - ACUCACACCACUGCAUUCUCACCC GCAAGCACC-3'); and ESS1mt (5'-ACUCGCGCCGCUGCGUU CUCGCCCGCGAGCGCC-3').

A ESS1- ACUCACACCACUGCAUUCUCACCCGCAAGCACC ESS1mt - ACUCGCGCCGCUGCGUUCUCGCCCGCGAGCGCC
B

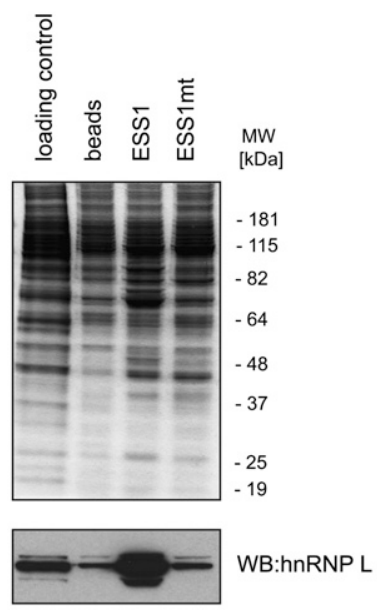

C

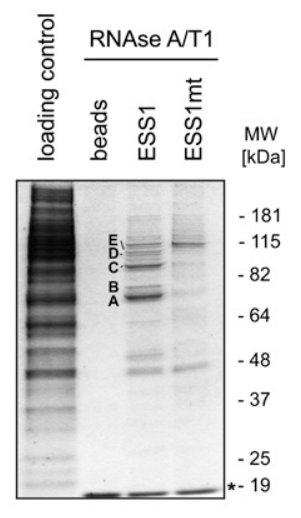

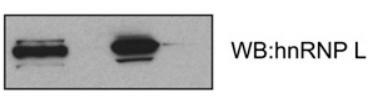

FIGURE 5. Isolation of proteins binding to a transcript derived from exon 4 of the CD45 exonic splicing silencer-ESS1 or a mutant version-ESS1mt. (A) Sequences of ESS1 and ESS1mt RNAs are shown. Mutated residues are in bold. (B) Standard and (C) RNase-assisted chromatography of ESS1 and ESS1mt transcripts in HeLa nuclear extracts. Bands denoted A, B, C, D, and E correspond to selected proteins highly enriched in the ESS1 chromatography, hnRNP K, hnRNP L, FUBP2, FUBP1, and FUBP3, respectively. (Bottom) hnRNP L Western blot analysis of the corresponding RNA chromatograms. $\left(^{*}\right)$ A band corresponding to RNase A/T1. 


\section{Western blot analysis}

RNA-bound proteins were separated using the NuPAGE Novex Bis-Tris system (Invitrogen). Proteins were visualized by GelCode Blue (Pierce). Selected bands were subjected to mass spectroscopy (at the BSRC Mass Spectrometry and Proteomics Facility, University of St Andrews). Alternatively, Western blot analysis was carried out with hnRNP L-specific monoclonal antibody 4D11 (Sigma-Aldrich), hnRNP I/PTB-specific monoclonal antibody SH54 (Abcam), and SF2/ASF-specific monoclonal antibody clone 96 (Hanamura et al. 1998).

\section{ACKNOWLEDGMENTS}

We are grateful to Juan Valcarcel (Center for Genomic Regulation) and to Sara Macias (Medical Research Council, Human Genetics Unit) for discussions and critical reading of the manuscript. This work was supported by Core funding from the Medical Research Council and a project grant from the Wellcome Trust, with additional funds from European Alternative Splicing Network-FP6 (Eurasnet).

Received February 20, 2010; accepted May 11, 2010.

\section{REFERENCES}

Baroni TE, Chittur SV, George AD, Tenenbaum SA. 2008. Advances in RIP-ChIP analysis: RNA-binding protein immunoprecipitationmicroarray profiling. Methods Mol Biol 419: 93-108.

Buratti E, Dork T, Zuccato E, Pagani F, Romano M, Baralle FE. 2001. Nuclear factor TDP-43 and SR proteins promote in vitro and in vivo CFTR exon 9 skipping. EMBO J 20: 1774-1784.

Buratti E, Muro AF, Giombi M, Gherbassi D, Iaconcig A, Baralle FE. 2004. RNA folding affects the recruitment of SR proteins by mouse and human polypurinic enhancer elements in the fibronectin EDA exon. Mol Cell Biol 24: 1387-1400.

Chi SW, Zang JB, Mele A, Darnell RB. 2009. Argonaute HITS-CLIP decodes microRNA-mRNA interaction maps. Nature 460: 479-486.

Cramer P, Caceres JF, Cazalla D, Kadener S, Muro AF, Baralle FE, Kornblihtt AR. 1999. Coupling of transcription with alternative splicing: RNA pol II promoters modulate SF2/ASF and 9G8 effects on an exonic splicing enhancer. Mol Cell 4: 251-258.

Dreyfuss G, Kim VN, Kataoka N. 2002. Messenger-RNA-binding proteins and the messages they carry. Nat Rev Mol Cell Biol 3: 195-205.

Ellington AD, Szostak JW. 1990. In vitro selection of RNA molecules that bind specific ligands. Nature 346: 818-822.

Ginisty H, Sicard H, Roger B, Bouvet P. 1999. Structure and functions of nucleolin. J Cell Sci 112: 761-772.

Glisovic T, Bachorik JL, Yong J, Dreyfuss G. 2008. RNA-binding proteins and post-transcriptional gene regulation. FEBS Lett 582: 1977-1986.

Grabowski PJ, Sharp PA. 1986. Affinity chromatography of splicing complexes: U2, U5, and U4 + U6 small nuclear ribonucleoprotein particles in the spliceosome. Science 233: 1294-1299.

Hanamura A, Caceres JF, Mayeda A, Franza BR, Krainer AR. 1998. Regulated tissue-specific expression of antagonistic pre-mRNA splicing factors. RNA 4: 430-444.

Hegarat N, Francois JC, Praseuth D. 2008. Modern tools for identification of nucleic acid-binding proteins. Biochimie 90: 1265-1272.

Heo I, Joo C, Kim YK, Ha M, Yoon MJ, Cho J, Yeom KH, Han J, Kim VN. 2009. TUT4 in concert with Lin 28 suppresses microRNA biogenesis through pre-microRNA uridylation. Cell 138: 696-708.

Houseley J, Tollervey D. 2009. The many pathways of RNA degradation. Cell 136: 763-776.

Kelly SM, Corbett AH. 2009. Messenger RNA export from the nucleus: A series of molecular wardrobe changes. Traffic 10: 1199-1208.
Kim VN, Han J, Siomi MC. 2009. Biogenesis of small RNAs in animals. Nat Rev Mol Cell Biol 10: 126-139.

Langland JO, Pettiford SM, Jacobs BL. 1995. Nucleic acid affinity chromatography: Preparation and characterization of doublestranded RNA agarose. Protein Expr Purif 6: 25-32.

Lavigueur A, La Branche H, Kornblihtt AR, Chabot B. 1993. A splicing enhancer in the human fibronectin alternate ED1 exon interacts with SR proteins and stimulates U2 snRNP binding. Genes Dev 7: 2405-2417.

Licatalosi DD, Mele A, Fak JJ, Ule J, Kayikci M, Chi SW, Clark TA, Schweitzer AC, Blume JE, Wang X, et al. 2008. HITS-CLIP yields genome-wide insights into brain alternative RNA processing. Nature 456: 464-469.

Lorenz C, von Pelchrzim F, Schroeder R. 2006. Genomic systematic evolution of ligands by exponential enrichment (Genomic SELEX) for the identification of protein-binding RNAs independent of their expression levels. Nat Protoc 1: 2204-2212.

Martin KC, Ephrussi A. 2009. mRNA localization: Gene expression in the spatial dimension. Cell 136: 719-730.

Matunis MJ, Matunis EL, Dreyfuss G. 1994. Isolation and characterization of RNA-binding proteins from Drosophila melanogaster. Methods Cell Biol 44: 191-205.

Melton AA, Jackson J, Wang J, Lynch KW. 2007. Combinatorial control of signal-induced exon repression by hnRNP L and PSF. Mol Cell Biol 27: 6972-6984.

Michlewski G, Guil S, Semple CA, Caceres JF. 2008. Post-transcriptional regulation of miRNAs harboring conserved terminal loops. Mol Cell 32: 383-393.

Min H, Turck CW, Nikolic JM, Black DL. 1997. A new regulatory protein, KSRP, mediates exon inclusion through an intronic splicing enhancer. Genes Dev 11: 1023-1036.

Niranjanakumari S, Lasda D, Brazas R, Garcia-Blanco MA. 2002. Reversible cross-linking combined with immunoprecipitation to study RNA-protein interactions in vivo. Methods 26: 182-190.

Rothrock CR, House AE, Lynch KW. 2005. HnRNP L represses exon splicing via a regulated exonic splicing silencer. EMBO J 24: 27922802.

Ruby SW, Goelz SE, Hostomsky Z, Abelson JN. 1990. Affinity chromatography with biotinylated RNAs. Methods Enzymol 181: 97-121.

Sanford JR, Wang X, Mort M, Vanduyn N, Cooper DN, Mooney SD, Edenberg HJ, Liu Y. 2009. Splicing factor SFRS1 recognizes a functionally diverse landscape of RNA transcripts. Genome Res 19: 381-394.

Singer BS, Shtatland T, Brown D, Gold L. 1997. Libraries for genomic SELEX. Nucleic Acids Res 25: 781-786.

Singh R, Valcarcel J. 2005. Building specificity with nonspecific RNAbinding proteins. Nat Struct Mol Biol 12: 645-653.

Sonenberg N, Hinnebusch AG. 2009. Regulation of translation initiation in eukaryotes: Mechanisms and biological targets. Cell 136: 731-745.

Tuerk C, Gold L. 1990. Systematic evolution of ligands by exponential enrichment: RNA ligands to bacteriophage T4 DNA polymerase. Science 249: 505-510.

Ule J, Jensen KB, Ruggiu M, Mele A, Ule A, Darnell RB. 2003. CLIP identifies Nova-regulated RNA networks in the brain. Science 302: $1212-1215$

Ule J, Jensen K, Mele A, Darnell RB. 2005. CLIP: A method for identifying protein-RNA interaction sites in living cells. Methods 37: 376-386.

Wahl MC, Will CL, Luhrmann R. 2009. The spliceosome: Design principles of a dynamic RNP machine. Cell 136: 701-718.

Yeo GW, Coufal NG, Liang TY, Peng GE, Fu XD, Gage FH. 2009. An RNA code for the FOX2 splicing regulator revealed by mapping RNA-protein interactions in stem cells. Nat Struct Mol Biol 16: 130-137.

Zisoulis DG, Lovci MT, Wilbert ML, Hutt KR, Liang TY, Pasquinelli AE, Yeo GW. 2010. Comprehensive discovery of endogenous Argonaute binding sites in Caenorhabditis elegans. Nat Struct Mol Biol 17: 173-179. 

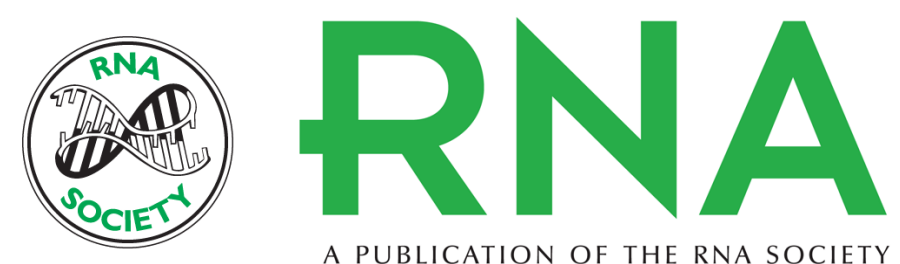

A PUBLICATION OF THE RNA SOCIETY

\section{RNase-assisted RNA chromatography}

Gracjan Michlewski and Javier F. Cáceres

RNA 2010 16: 1673-1678 originally published online June 22, 2010

Access the most recent version at doi:10.1261/rna.2136010

\section{References This article cites 38 articles, 12 of which can be accessed free at: http://rnajournal.cshlp.org/content/16/8/1673.full.html\#ref-list-1}

Open Access Freely available online through the RNA Open Access option.

License Freely available online through the RNA Open Access option.

Email Alerting Receive free email alerts when new articles cite this article - sign up in the box at the Service top right corner of the article or click here. 